\title{
The effect of drying process on the pigment content and composition of table beet varieties
}

\author{
Takács-Hájos, M. \\ University of Debrecen, Centre of Agricultural Science and Engineering, Faculty of Agriculture, Institute of \\ Horticulture, 138. Böszörményi str.,Debrecen,H-4032,Hungary,e-mail: hajos@agr.unideb.hu
}

\begin{abstract}
Summary: The food industry requires natural colouring agents in increasing quantities. Beet root is highly adapted to this purpose with its red (betacyanin) and yellow (betaxanthin) pigments suitable for numerous products. The two pigments are, however, very heat-sensitive depending not only on the method of drying as well.

In our experiment we tested 6 table beet varieties with vacuum drying (instrument: Eurovac KIT-150) and obtained very big differences in the suitability of varieties for drying. The less colour loss was measured in Bordó (16.84\%), while Rubin and Cylindra indicated 45.15 and $47.18 \%$ loss respectively.

During the drying raw material with higher colour content produced higher rate of pigment loss $(\mathrm{r}=0.880)$. In our experiment we found adverse effects on colour material and dry matter content in the fresh beet root. The variety with higher solids (mainly sugar) resulted in higher pigment loss $(r=-0.847)$ during the vacuum drying process. Furthermore, we stated that the yellow pigments (betaxanthin) were less heat sensitive during drying than the red (betacyanin) ones.

For the production of beet root powder varieties of high pigment content but low water soluble solids content (sugar) are needed.
\end{abstract}

Key words: table beet, vacuum drying, natural pigment, water soluble solids content, betacyanin, betaxanthin, heat sensitivity, pigment loss

\section{Introduction}

Recently rigorous prohibitive measures have been introduced in the use of additives - including colouring agents - in food industry. It is well known that many of the artificial colouring agents are unwholesome. Table beet root pigments contain betalaines consisting of a mixture of yellow betaxanthins $(\mathrm{BX})$ and red betacyanins $(\mathrm{BC})$. It is their ratio $(\mathrm{BC} / \mathrm{BX})$ that determines the intensity of inner colour in the root. Red beet roots are excellent natural sources of colouring agents used not only in the food industry but also in cosmetics (make up, powder, etc.). The term betacyanin refers collectively to several red colour components. These compounds degrade easily at high temperature, intense light and humid atmosphere (Elbe et al., 1974). They are the most stable in slightly acid medium (Takácsné Hájos and Gyuris, 1994). Betanin is the red pigment found in the highest quantity mounting to $75-95 \%$ of the total pigment content (Nagy-Gasztonyi et al., 2001). During processing betanin is the slowest to degrade, so, it is desired in the highest possible quantity in the raw material. The colouring agent produced of table beet roots is marketed under the label of betanin E 162 and used for colouring bottled cherry, soya products, fruit yoghurt, ice-cream, sausage and tinned beef. It is meant to limit the use of azocolour amaranth E 123 (naphtol red S). Juice can also be made of beet roots by lactic acid fermentation. Table beet pigments are used as powder and colour concentrations produced by fermentation. When fermented the extraction is affected considerably by the species of the yeast and the quantity of sugars in the root (Drdak et al., 1992).

Table beet root due to its pigment content is especially adapted to produce natural food colours and in the same time, it has favourable nutritive - physiological effects. Beet root has considerable fibre (0.9-2.53\%), potassium (336 mg $\left.100 \mathrm{~g}^{-1}\right)$, and magnesium ( $25 \mathrm{mg}^{100 \mathrm{~g}^{-1}}$ ) contents. Beet root in proper doses can increase the mineral element supply of the organism.

A close correlation was found between the red pigment content (betacyanin) and the total antioxidant content $(\mathrm{r}=$ 0.71). It proves that cultivars of intensive red inner colour are more capable to catch free radicals, that is, they are more valuable from nutritional-physiological points (TakacsHajos et al., 2004; Jiratana and Liu, 2007).

Tests revealed that the pigment loss caused by drying is significantly affected by the variety and its genetically fixed pigment content. It is well known that the red and yellow pigments, respectively, are determined by several components of different heat sensitivity (Nagy-Gasztonyi et al., 2001). This could explain the difference between varieties.

\section{Materials and methods}

In the trial we used 6 varieties (Favorit, Rubin, Detroit, Bordó, Cylindra and Little Ball, all of them in Hungarian 
seed trade), in 4 repetition. We measured the water soluble solids content of fresh root $(\%)$ by refractometer and the red (betacyanins) and yellow (betaxanthins) pigment content $\left(\mathrm{mg} 100 \mathrm{~g}^{-1}\right)$ of root. For pigment analysis we used a spectrophotometric method (Takácsné Hájos and Gyuris, 1994). The absorbance values of the two colour substances were determined (betacyanin - $537 \mathrm{~nm}$, betaxantin - 478 $\mathrm{nm}$ ), finally measurements were taken at $600 \mathrm{~nm}$, too. The colouring substance concentration was calculated by Nilsson's method (Nilsson, 1970).

The drying process was carried out by a vacuum dryer (Eurovac KIT-150). Before the drying process the samples were washed, pealed and put on the tray of the instrument. The parameters of the drying process were the following: vacuum: 0.2 bar; temperature: $48^{\circ} \mathrm{C}$; the drying period 75.5 hours. Samples were dried to $12-15 \%$ water content. After milling the colour substance quantities were measured by the previous method. The pigment content was given in $\mathrm{mg}$ pro $100 \mathrm{~g}$ powder. The same method was used for the measuring of colour content as in the fresh samples.

For the statistical evaluation - standard deviation and correlation between the parameters - we used the programs of Excel.

\section{Results and discussion}

In our trials the variety Cylindra showed the highest heat sensitivity as nearly half of the pigments decomposed (Table 1). The variety Rubin had similar instability. Of the tested 6 varieties Bordó proved to be the best with $16.84 \%$ pigment loss.

Table 1. Betacyanin and dry matter content in the table beet varieties

\begin{tabular}{|c|c|c|c|c|}
\hline \multirow{2}{*}{ Varieties } & \multicolumn{2}{|c|}{ Betacyanin content $\left(\mathrm{mg} \mathrm{100g}^{-1}\right)$} & \multirow{2}{*}{$\begin{array}{c}\text { Colour } \\
\text { loss } \\
(\%)\end{array}$} & \multirow{2}{*}{$\begin{array}{c}\text { Dry matter } \\
\text { content } \\
(\%)\end{array}$} \\
\hline & in fresh root & in powder & & \\
\hline Favorit & $533.23 \pm 47.75$ & $367.96 \pm 21.21$ & 30.99 & $10.85 \pm 0.63$ \\
\hline Rubin & $713.19 \pm 21.15$ & $391.09 \pm 14.29$ & 45.16 & $9.52 \pm 0.37$ \\
\hline Detroit & $449.54 \pm 27.07$ & $290.26 \pm 18.71$ & 35.43 & $10.45 \pm 1.64$ \\
\hline Bordó & $418.18 \pm 12.25$ & $347.76 \pm 29.87$ & 16.84 & $12.23 \pm 0.23$ \\
\hline Cylindra & $725.4 \pm 8.24$ & $378.55 \pm 12.49$ & 47.81 & $9.20 \pm 0.14$ \\
\hline Little Ball & $566.35 \pm 31.06$ & $364.54 \pm 20.39$ & 35.63 & $8.75 \pm 0.48$ \\
\hline
\end{tabular}

Our results indicated (Table 2) a close negative correlation between betacyanin (BC) content in the fresh root and dry matter content $(\mathrm{r}=\mathbf{- \mathbf { 0 . 7 3 9 }})$. There is adverse effect on the colour material in the powder and the $\mathrm{BC}$ content in the fresh root $(r=\mathbf{0 . 7 4 9})$. It can be explained that the higher amount of dry matter content (mainly sugar) increases colour loss because during the drying process it turns brown, deteriorating the colour intensity of the powder. This theory is supported by the adverse effect of betacyanin content of the fresh root and dry matter content.
Table 2. Correlation between different quality parameters $(\mathrm{n}=24)$

\begin{tabular}{|l|c|c|c|c|}
\hline & $\begin{array}{c}\text { BC in fresh } \\
\text { root }\end{array}$ & $\begin{array}{c}\text { BC in } \\
\text { powder }\end{array}$ & $\begin{array}{c}\text { Colour loss } \\
(\%)\end{array}$ & $\begin{array}{c}\text { Dry matter } \\
\text { content (\%) }\end{array}$ \\
\hline BC in fresh root & - & 0.749 & 0.880 & -0.739 \\
\hline BC in powder & & - & 0.367 & -0.369 \\
\hline Colour loss (\%) & & & - & -0.847 \\
\hline Dry matter content & & & & - \\
\hline
\end{tabular}

In our hypothesis the two quality parameters (colour and sugar content) exist differently so the very good inner colour of root seems to have lower sugar content. Row material with higher sugar content is very useful for canning, while the other varieties with lower saccharose content for drying.

Data of betaxanthin content in fresh root and powder in Table 3 indicate that the betaxanthin colour loss is less than that of the betacyain. In this way we can state that betacyanin is more heat sensitive then betaxanthin.

Table 3. Betaxanthin content in different table beet varieties

\begin{tabular}{|l|c|c|c|}
\hline \multirow{2}{*}{\multicolumn{1}{|c|}{ Varieties }} & \multicolumn{2}{|c|}{ Betaxanthin content $\left(\mathbf{m g ~ 1 0 0 g}^{-1}\right)$} & \multirow{2}{*}{ Colour loss (\%) } \\
\cline { 2 - 4 } & in fresh root & in powder & \\
\hline Favorit & $551.35 \pm 46.81$ & $410.98 \pm 25.15$ & $\mathbf{2 5 . 4 6}$ \\
\hline Rubin & $793.22 \pm 30.20$ & $450.71 \pm 26.43$ & $\mathbf{4 3 . 1 8}$ \\
\hline Detroit & $464.81 \pm 16.28$ & $342.2 \pm 26.66$ & $\mathbf{2 6 . 3 8}$ \\
\hline Bordó & $471.56 \pm 27.44$ & $395.34 \pm 23.04$ & $\mathbf{1 6 . 1 6}$ \\
\hline Cylindra & $713.42 \pm 11.48$ & $438.27 \pm 18.79$ & $\mathbf{3 8 . 5 7}$ \\
\hline Little Ball & $635.36 \pm 40.39$ & $446.31 \pm 20.99$ & $\mathbf{2 9 . 7 5}$ \\
\hline
\end{tabular}

\section{Conclusions}

Vacuum drying is recommended to produce beet root powder in large quantities as lower temperatures can be used (48 ${ }^{\circ} \mathrm{C}$ ). For this purpose it is important to choose proper varieties as the higher sugar content turns brown during the process and decreases the value of the product considerably. The same raw material is, however, highly advantageous for salads and fresh consumption. The drying industry requires raw material of different type. Varieties should be tested for these parameters.

Our trials showed considerable differences in this point. The rate of pigment loss varied from $16.84 \%$ (Bordó) to $47.18 \%$ (Cylindra). This may correlate with the genetically determined pigment composition of the variety and the sugar content in solution.

The inner colour intensity of a variety is determined by the ratio of red $(\mathrm{BC})$ and yellow $(\mathrm{BX})$ pigments $(\mathrm{BC} / \mathrm{BX})$. A higher proportion value should be aimed at with a more intensive red colour. It is all the more important as our measurements indicated higher heat-sensitivity in the red components when compared to the yellow ones. 
Beet root used for drying should contain higher betacyanin content and lower water soluble solids (sugar).

\section{References}

Drdak, M., Alfamirano, R. C., Rajnokova. A., Simko, P., Karavicova, J. \& Benkovszka, D. (1992): Red beet pigment composition. Effect of fermentation by different strains of Saccharomicetes cerevisiae. J. Food. Sci. 57: 935-936.

Elbe, J.H. von, Maing, J.Y. \& Amundson, C.H. (1974): Colour stability of betanin. Journal of Food Science. 39: 334.

Jiratanan, T. \& Liu, R.H.( 2004): Antioxidant Activity of Processed Table Beets (Beta vulgaris var, conditiva) and Green Beans (Phaseolus vulgaris L.). J. Agric Food Chem., 52. (9): 2659-2670.
Nagy-Gasztonyi, M., Daood, H., Takács ,Hájos M. \& Biacs, P. A. (2001): Comparison of red-beet varieties on the basis of their pigment-components. Journal of the Science of Food and Agriculture. 81: 932-933.

Nilsson, T. (1970): Studies into the pigments in beetroot (Beta vulgaris L. ssp. vulgaris var. rubra L.). Lantbrukhogskolans Annaler. 36: 179-219.

Takács, Hajos M., Szőllősi Varga, I., Lugasi, A., Fehér, M. \& Stefanovits, Bányai É. (2004): Correlation between pigment contents and FRAP values in beet root (Beta vulgaris ssp. esculenta var. rubra). International Journal of Horticulture Science.10: (4.) 85-91.

Takácsné, Hájos M. \& Gyuris, K. (1994): The effect of different temperatures and $\mathrm{pH}$ values on colour intensity in table beet root. Bulletin of the Vegetable Crops Research Institute. Kecskemét. 26: $129-140$ 